Review

\title{
Role of the nitric oxide-soluble guanylyl cyclase pathway in obstructive airway diseases
}

\author{
Lisa L. Dupont ${ }^{a}$, Constantinos Glynos ${ }^{\text {b, c }}$, Ken R. Bracke a, Peter Brouckaert ${ }^{\text {d, e }}$, \\ Guy G. Brusselle ${ }^{\mathrm{a}, *}$ \\ a Laboratory for Translational Research in Obstructive Pulmonary Diseases, Department of Respiratory Medicine, Ghent University Hospital, Ghent, Belgium \\ b George P. Livanos and Marianthi Simou Laboratories, Evangelismos Hospital, 1st Department of Pulmonary and Critical Care, University of Athens, \\ Athens, Greece \\ ${ }^{\mathrm{c}}$ Laboratory of Molecular Pharmacology, Department of Pharmacy, University of Patras, Patras, Greece \\ d Department of Biomedical Molecular Biology, Ghent University, Ghent, Belgium \\ e Department of Molecular Biomedical Research, VIB, Ghent, Belgium
}

\section{A R T I C L E I N F O}

\section{Article history:}

Received 3 July 2014

Received in revised form

9 July 2014

Accepted 9 July 2014

Available online 17 July 2014

\section{Keywords:}

COPD

Asthma

Nitric oxide

Soluble guanylyl cyclase

\begin{abstract}
A B S T R A C T
Nitric oxide (NO) is a gaseotransmitter, which is involved in many signaling processes in health and disease. Three enzymes generate NO from L-arginine, with citrulline formed as a by-product: neuronal NO synthase (nNOS or NOS1), endothelial NOS (eNOS or NOS3) and inducible NOS (iNOS or NOS2). NO is a ligand of soluble guanylyl cyclase (sGC), an intracellular heterodimer enzyme that catalyzes the conversion of guanosine triphosphate (GTP) to cyclic GMP (cGMP). cGMP further activates protein kinase G that eventually reduces the smooth muscle tone in bronchi or vessels. Phosphodiesterase $5\left(\mathrm{PDE}_{5}\right)$ degrades cGMP to GMP. However, NO reacts with superoxide anion $\left(\mathrm{O}_{2}^{-}\right)$, leading to formation of the proinflammatory molecule peroxynitrite.

Under physiological conditions, NO plays a homeostatic bronchoprotective role in healthy subjects.

In obstructive airway diseases, NO can be beneficial by its bronchodilating effect, but could also be detrimental by the formation of peroxynitrite. Since asthma and COPD are associated with increased levels of exhaled NO, chronic inflammation and increased airway smooth muscle tone, the NO/sGC/cGMP pathway could be involved in these highly prevalent obstructive airway diseases. Here we review the involvement of NO, NO synthases, guanylyl cyclases, cGMP and phophodiesterase- 5 in asthma and COPD and potential therapeutic approaches to modulate this pathway.
\end{abstract}

(c) 2014 Elsevier Ltd. All rights reserved.

\section{Nitric oxide (NO) and NO synthases}

\subsection{Introduction}

Nitric oxide (NO) is the first identified gaseotransmitter, which is involved in many diverse signaling processes including inflammation, smooth muscle tone and neurotransmission [1,2]. Within the respiratory tract, the main sources of NO are airway epithelial cells and endothelial cells [3,4]. Under physiological conditions, NO is present in the exhaled breath [5].

The synthesis of NO is catalyzed by 3 NO synthase (NOS) isoforms. Neuronal NOS (nNOS or NOS1) and endothelial NOS (eNOS

\footnotetext{
* Corresponding author. Tel.: +32 93322604.

E-mail address: guy.brusselle@ugent.be (G.G. Brusselle).
}

or NOS3) are constitutively expressed and their activity is regulated by intracellular calcium concentrations and calmodulin [6,7]. In an alternative pathway, eNOS can be activated by phosphorylation which renders it calcium-independent [8]. In conditions of oxidative stress and depletion of the co-factor BH4 (tetrahydrobiopterin), eNOS can become uncoupled resulting in the production of superoxide instead of NO [8]. Inducible NOS (iNOS or NOS2) is independent of calcium and is regulated by cytokines and proinflammatory stimuli [9]. However, this distinction is not that strict, since the activity of nNOS and eNOS, also referred to as "constitutive NOS (cNOS)", can be induced by several cytokines (IL-1 $\beta$, IFN- $\gamma$, TNF- $\alpha$ ) $[10,11]$; while iNOS may be constitutively expressed at certain sites including the airway epithelium [12]. No can also be produced by various enzymes, starting from nitrite [13].

An overview of the expression of the 3 isoforms of NO synthase in human and murine lung tissue is shown in Table 1. 
Table 1

Lung expression of the 3 isoforms of NO synthase (nNOS, iNOS and eNOS) in human subjects and murine models.

\begin{tabular}{|c|c|c|c|c|c|}
\hline Patients/model & Tissue & nNOS & iNOS & eNOS & Reference \\
\hline \multicolumn{6}{|l|}{ HUMAN } \\
\hline Patients with COPD/smokers/nonsmokers & Peripheral lung tissue & $\uparrow$ GOLD 2,3,4 (M + P) & $\begin{array}{l}\uparrow \text { GOLD 2,3,4 (M) } \\
\uparrow \text { GOLD 1, 2,3,4 (P) }\end{array}$ & $\begin{array}{l}\downarrow \text { GOLD } 3,4(\mathrm{M}) \\
\downarrow \text { GOLD } 4(\mathrm{P})\end{array}$ & [10] \\
\hline Patients with COPD/smokers/nonsmokers & Bronchial submucosa & ND & $\uparrow$ Smokers, COPD (P) & $\uparrow$ Smokers, COPD (P) & {$[16]$} \\
\hline Patients with severe COPD/smokers & Alveolar wall & ND & $\begin{array}{l}\uparrow \text { Severe COPD (P) } \\
\text { (mainly type II pneumocytes) }\end{array}$ & ND & {$[17]$} \\
\hline \multicolumn{6}{|l|}{ MICE } \\
\hline After 8 months CS & Lung homogenate & ND & $\uparrow(\mathrm{P})$ & $\downarrow(\mathrm{P})$ & [19] \\
\hline Elastase-induced emphysema & $\begin{array}{l}\text { Lung homogenate } \\
\text { day } 1-3-7-20\end{array}$ & $\downarrow$ At d1 and d7 (M) & $\uparrow(\mathrm{M}+\mathrm{P})$ & $\uparrow(\mathrm{M}+\mathrm{P})$ & [21] \\
\hline
\end{tabular}

$\mathrm{ND}=$ not determined, $\mathrm{M}$ : mRNA, P:protein, $\mathrm{CS}$ : cigarette smoke.

\subsection{Chronic obstructive pulmonary disease}

Chronic obstructive pulmonary disease (COPD) is mainly caused by smoking cigarettes, which are an exogenous source of NO. Ansarin et al. [14] have analyzed the exhaled nitric oxide (eNO) levels in patients with COPD, patients with asthma and healthy controls. Patients with COPD had higher eNO levels than healthy controls, but lower levels than patients with asthma. Lung function parameters such as forced expiratory volume in $1 \mathrm{~s}\left(\mathrm{FEV}_{1}\right)$ and carbon monoxide diffusing capacity $\left(\mathrm{DL}_{\mathrm{CO}}\right)$ were inversely correlated with eNO levels in patients with COPD. In contrast to patients with asthma, the use of inhaled corticosteroids had no significant influence on eNO levels in patients with COPD [14]. Brindicci et al. measured eNO at multiple expired flows to make a distinction between alveolar and bronchial NO and found that COPD is associated with elevated alveolar NO [15].

In peripheral lung tissue and bronchial submucosa of patients with COPD, iNOS expression was significantly increased, irrespective of the GOLD stage $[10,16]$. Patients with severe COPD had increased NNOS $^{+}$cells in the alveolar wall and most of these cells were type II pneumocytes [17]. These results are in agreement with the observed increased alveolar NO in patients with COPD [15]. In bronchial submucosa, there was also an effect of smoking, since smokers without airflow limitation had increased iNOS levels [16]. The expression of iNOS was increased in bronchial smooth muscle cells of patients with COPD and was correlated with the degree of airflow limitation [18].

The expression levels of eNOS showed a discrepancy between the two localizations. In peripheral lung tissue, eNOS protein levels were similar between nonsmokers, smokers without airflow limitation and patients with COPD GOLD 1, 2 and 3. Remarkably, eNOS levels were significantly decreased in patients with severe COPD GOLD 4, probably caused by the destruction of the alveolar walls $[10,19]$. The levels of eNOS behaved similar to iNOS in bronchial submucosa [16].

The levels of nNOS were increased in peripheral lung tissue of patients with COPD GOLD stages 2, 3 and 4 compared with nonsmokers. Moreover, nNOS protein expression and disease severity (measured by $\mathrm{FEV}_{1} \%$ and $\mathrm{FEV}_{1} / \mathrm{FVC}$ ) were significantly correlated [10].

Similar to the results in human peripheral lung tissue [10], the levels of iNOS in murine lung homogenate were increased after 8 months cigarette smoke (CS) exposure, while the levels of eNOS were decreased [19]. In contrast to eNOS knockout mice, iNOS knockout mice were protected against the development of CSinduced emphysema. Treating wild-type mice with an iNOS inhibitor after 8 months CS exposure even reversed the lung damage and significantly downregulated the amount of granulocytes, macrophages and T-lymphocytes in the lung [19].

A chronic, iNOS-related inflammation, hypertrophy and hyperplasia of alveolar type II cells and several abnormalities in pulmonary structure and function develop in mice deficient in Surfactant Protein D (SP-D) [20]. SP-D and iNOS double knockout mice (DiNOS) maintained hyperplasia of alveolar type II cells, but they had a reduced inflammation, correction of the alveolar structural abnormalities and a restored lung function, compared with SP-D single KO mice. So by producing NO under pathological conditions, iNOS is involved in inflammation, development of structural abnormalities and lung function [20]. These findings and the observed increased iNOS expression in patients with COPD suggest that the inhibition of iNOS may be a potential therapy for patients with COPD $[19,20]$. However, in a murine model of elastase-induced emphysema [21], with increased expression of iNOS and eNOS, inhibition of iNOS decreased the amount of protein nitration, but had no effect on inflammation or development of emphysema. Inhibition of eNOS had overall no effect [21].

\subsection{Asthma}

In patients with asthma, especially in allergic asthmatics with eosinophilic airway inflammation, the levels of nitric oxide in exhaled air are significantly elevated compared with healthy subjects [22-24]. Moreover, lung function parameters such as $\mathrm{FEV}_{1}$ and $\mathrm{DL}_{\mathrm{CO}}$ were inversely correlated with exhaled NO levels [14]. This increased flux of NO from the airways was significantly decreased after inhalation of aminoguanidine, a relatively selective iNOS inhibitor [25]. The expression of iNOS was increased in airway epithelial cells and inflammatory cells from patients with asthma compared with healthy subjects, suggesting that this enzyme plays an important role in the production of NO in pathological conditions [26,27]. Increased FeNO levels are a predictor of response to inhaled corticosteroids in patients with asthma [28]. iNOS levels in corticosteroid-treated asthmatics were significantly decreased compared to noncorticosteroid treated asthmatics [29]. Treatment of asthma patients with a selective iNOS inhibitor, GW274150, significantly reduced FeNO levels. However, this reduction in FeNO levels did not lead to a change in early or late responses to allergen challenge, or to a change in numbers of inflammatory cells in bronchoalveolar lavage (BAL) [30]. This suggests that therapeutic treatment with an iNOS inhibitor would not be beneficial in patients with asthma.

In a murine model of allergic asthma, the pharmacological inhibition of iNOS by L-NAME or aminoguanidine significantly decreased the number of eosinophils and lymphocytes in BAL fluid in OVA-challenged mice compared with non-treated mice [31]. Also airway hyperreactivity (AHR) and mucus secretion were significantly decreased in OVA-challenged mice after treatment with an iNOS inhibitor. In the same study, number of BAL cells, AHR and mucus secretion were not different between iNOS knockout and wild-type mice, suggesting that the lack of iNOS in these constitutive knockout animals is probably compensated by other mechanisms. In another study using the OVA model of allergic asthma, no differences in AHR were observed in iNOS knockout 
mice compared with wild-type mice. Although iNOS knockout mice developed a similar degree of inflammation as the wild-type controls, the deficiency of iNOS resulted in reduced eosinophils in BAL and in peripheral blood [32].

\section{Oxidative/nitrative stress in obstructive airway diseases}

Reactive oxygen species (ROS) are unstable molecules with an unpaired electron that can be generated endogenously by mitochondrial electron transport during respiration or during activation of inflammatory cells, and exogenously by cigarette smoke or air pollutants. These small reactive signaling molecules can oxidize proteins, lipids or DNA, leading to cell dysfunction and cell death. Also reactive nitrogen species (RNS), such as the highly pro-inflammatory molecule peroxynitrite, can cause tissue injury in various organs. Normally, they are counterbalanced by antioxidants and rapidly removed from the body. An imbalance between ROS/RNS and antioxidants leads to oxidative/nitrative stress [33-35]. Both oxidative and nitrative stress have been linked with inflammatory, obstructive airway diseases, including asthma and COPD [36,37].

Activated inflammatory cells such as macrophages and neutrophils produce increased levels of NO and ROS (superoxide $\left(\mathrm{O}_{2}^{--}\right)$and hydrogen radical ( $\left.\mathrm{HO}^{\circ}\right)$ ) (Fig. 1 ). NO rapidly reacts with $\mathrm{O}_{2}^{--}$to form the pro-inflammatory molecule peroxynitrite. Peroxynitrite alters the function of proteins by nitration of tyrosine residues. Currently, 3-nitrotyrosine is measured as a footprint of peroxynitrite release. Using a new noninvasive technique, Osoata et al. were able to measure peroxynitrite in exhaled breath condensate [38]. The levels of peroxynitrite were significantly higher in patients with COPD compared with smokers and healthy controls [38].

\section{Soluble guanylyl cyclase}

Guanylyl cyclases (GCs), members of the family of nucleotide cyclizing enzymes, are widely distributed signal-transduction enzymes that catalyze the conversion of GTP to cGMP.
Both transmembrane and soluble forms of guanylyl cyclases exist. The transmembrane, particulate GC (pGC) acts as a receptor for hormones such as atrial, brain (B-type) and C-type natriuretic peptides. For further information on this transmembrane form of GC, we refer the reader to an excellent review [39].

Soluble GC (sGC) is an intracellular receptor for gaseous ligands (NO and to a minor extent $\mathrm{CO}$ ) and is able to associate with the plasma membrane through protein-protein interactions in $\mathrm{Ca}^{2+}$ dependent manner [40]. sGC is a heterodimer, consisting of an $\alpha$ subunit and a $\beta$-subunit. There are 2 forms of the $\alpha$-subunit ( $\alpha 1$ and $\alpha 2$ ) and of the $\beta$-subunit ( $\beta 1$ and $\beta 2$ ), but only $\alpha 1 \beta 1$ and $\alpha 2 \beta 1$ are active. $\alpha 1 \beta 1$ and $\alpha 2 \beta 1$ are equally present in the brain, while $\alpha 1 \beta 1$ is the most prevalent form in other tissues such as the lung [41]. Both forms have a similar catalytic rate and sensitivity towards NO. The C-terminal catalytic domains of both isoforms are required to form a catalytic active centre. The $\beta$-subunit has an amino-terminal heme-binding domain. A heme moiety that interacts with the heme-binding domain, is essential for the sensing of NO, increasing the cGMP production from GTP [42]. The heme moiety is a large heterocyclic organic ring with a central metal ion (Fe). sGC is activated by nanomolar concentrations of NO in the presence of the reduced $\mathrm{Fe}^{2+}$ (ferrous) heme moiety, while oxidized, $\mathrm{Fe}^{3+}$ (ferric) heme is insensitive to NO (Fig. 2). Moreover, the oxidized heme rapidly released from the protein, resulting in the exposure of an ubiquitination site on the protein moiety, which leads to ubiquitination and proteolytic degradation of the enzyme. Similar to oxidized heme, heme-deficient SGC is unresponsive to NO. Oxidation is induced by exogenous molecules, such as ODQ $(1 \mathrm{H}-[1,2,4]$ oxadiazolo-[4, 3-a]quinoxalin-1-one), and by endogenous molecules, including reactive oxygen species (ROS) and reactive nitrogen species (RNS) [40].

Activation of sGC induces the generation of cyclic guanosine monophosphate (cGMP), phosphorylation of protein kinase G (PKG) and changes in activity of effector proteins such as phosphodiesterases (PDE), ion channels and ion pumps [43]. This pathway eventually leads to dilation of bronchi (bronchodilation) or vessels (vasodilation).

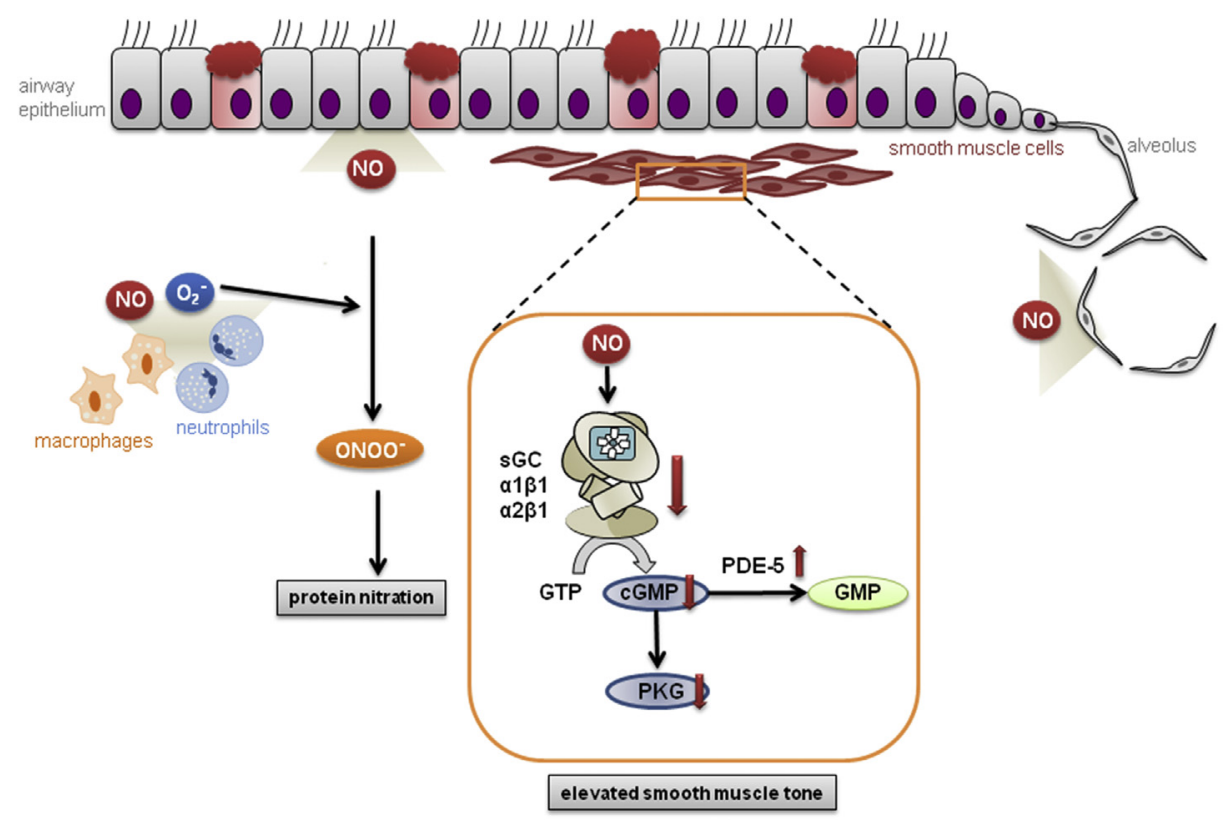

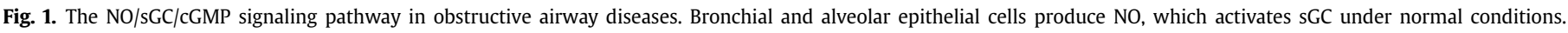

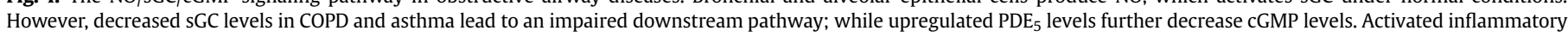

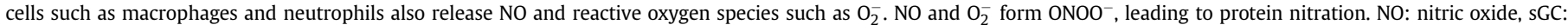

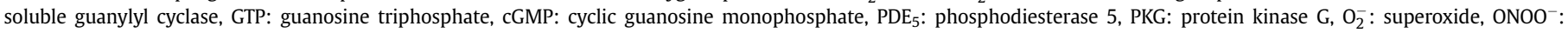
peroxynitrite. 


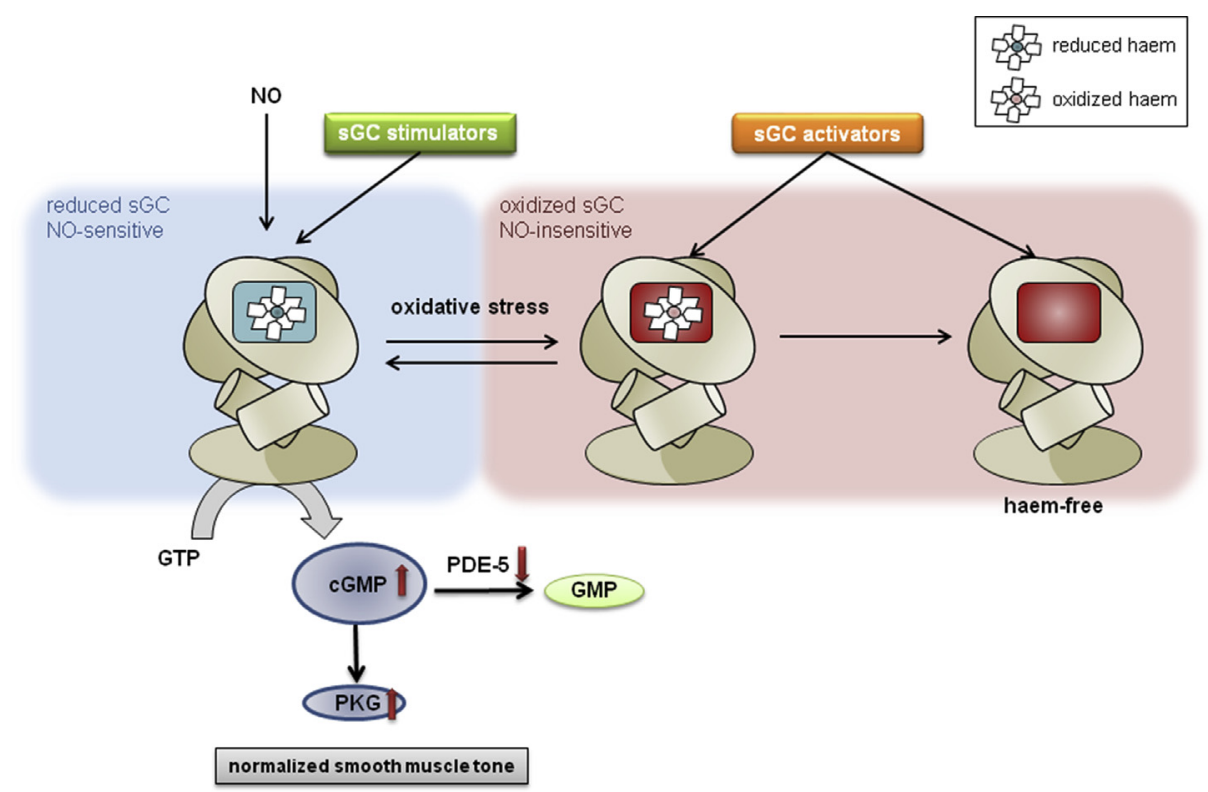

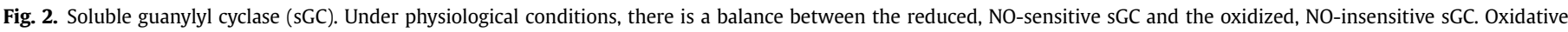

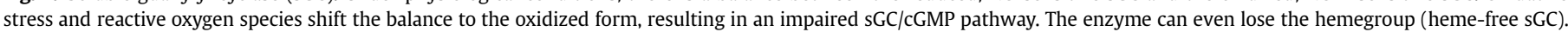

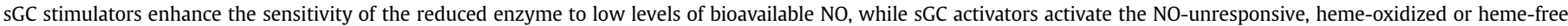

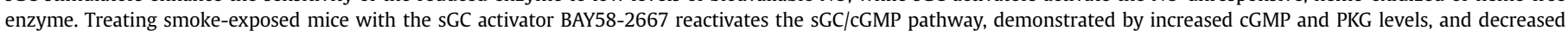
PDE-5 levels; leading to a normalized smooth muscle tone [45].

In patients with asthma, bronchodilation is impaired, despite the presence of large amounts of NO in the airways that could activate SGC and cause relaxation of the smooth muscle. In a murine model of allergic asthma, the levels of $\mathrm{sGC} \alpha 1, \alpha 2$ and $\beta 1$ were reduced in the lungs, both on mRNA and protein level [44]. Mice treated with the selective SGC inhibitor ODQ had increased airway reactivity to methacholine compared with sham-treated mice [44]. This finding suggests that SGC could be inhibited in patients with asthma, leading to the observed airway hyperresponsiveness. Also in patients with COPD, the lungs contain ample amounts of NO, but the airway tone remains elevated [14]. Patients with COPD have decreased pulmonary mRNA and protein levels of SGC which are correlated with disease severity [45]. The levels of sGC are also decreased in CS-exposed mice [45] CS-exposed mice deficient for the SGC $\alpha 1$ subunit had a significantly higher airway resistance compared with CS-exposed wild-type mice (Fig. 1). These results indicate that sGC downregulation due to CS exposure in humans and mice, emerges as an alternative pathophysiological mechanism of the airway hyperresponsiveness.

\section{Phosphodiesterase $5\left(\mathrm{PDE}_{5}\right)$}

Phosphodiesterase $5\left(\mathrm{PDE}_{5}\right)$ degrades cGMP to GMP; thereby impairing the downstream effects of cGMP (Fig. 1). Sildenafil, a short-acting inhibitor of $\mathrm{PDE}_{5}$, is already on the market for erectile dysfunction and pulmonary arterial hypertension and induces smooth muscle relaxation. Tadalafil is a long-acting inhibitor of $\mathrm{PDE}_{5}$. The effect of $\mathrm{PDE}_{5}$ inhibition was analyzed in guinea pigs exposed to lipopolysaccharide (LPS) and in sensitized guinea pigs exposed to ovalbumin [46]. Pretreatment with sildenafil inhibited the LPS-induced airway hyperreactivity, influx of leukocytes and generation of NO. Exposure to ovalbumin caused early- and latephase asthma responses which were not affected by sildenafil. However, AHR to histamine, leukocyte influx in BAL and increased NO metabolites in BAL were significantly attenuated in OVAexposed mice after treatment with sildenafil [46].
In a rat model of acrolein (a component of cigarette smoke) exposure, sildenafil suppressed the acrolein-induced airway inflammation and mucus production [47]. CS-exposed mice have increased $\mathrm{PDE}_{5}$ protein levels in the lung compared with airexposed mice [45]. These results suggest that $\mathrm{PDE}_{5}$ inhibitors have a therapeutic potential in airway diseases such as asthma and COPD. However, in contrast to OVA-challenged guinea pigs [46], OVA-challenged mice treated with sildenafil did not affect airway inflammation [48].

$\mathrm{PDE}_{5}$ inhibitors have not yet been tested in asthma or COPD for their anti-inflammatory properties. In contrast, $\mathrm{PDE}_{5}$ inhibitors have been investigated in patients with COPD and (concomitant) pulmonary hypertension. Treating patients with COPD-associated pulmonary hypertension with sildenafil or tadalafil did not improve exercise capacity or quality of life [49,50].

\section{Therapy}

Potential therapeutic approaches to modulate the NO/sGC/ cGMP pathway are activation of sGC by NO-donors, sGC stimulators and SGC activators; or inhibition of the inflammation-induced formation of NO by iNOS inhibitors.

\subsection{Nitric oxide donors}

A reduced bioavailability and/or responsiveness to endogenously produced NO contributes to the development of several pathologies, including pulmonary diseases.

NO-donors, such as organic nitrates, release NO by spontaneous decomposition or bioconversion, thereby activating the enzyme sGC. However, the use of NO-donors is limited because of the potential lack of response, the development of tolerance and the nonspecific interactions of NO with biomolecules (such as superoxide, leading to formation of peroxynitrite) [40]. Moreover, in the airways of patients with COPD or asthma, there are already large 
amounts of NO present that could activate sGC and induce smooth muscle relaxation.

\subsection{Inducible NO synthase inhibitors}

The research on the role of iNOS using animal models has given conflicting results. Given the species differences in the expression and regulation of iNOS, translational research is required to fully elucidate the function of iNOS in obstructive airway diseases. Treating asthma patients with the selective iNOS inhibitor GW274150 did not lead to a change in early or late responses to allergen challenge, or to a change in numbers of inflammatory cells in BAL [30].

In healthy subjects, physiological levels of NO are produced by eNOS and nNOS. In inflammatory conditions, NO levels increase mainly due to increased iNOS activity. By inhibiting iNOS, both the beneficial effects of NO through SGC and the pro-inflammatory effect of NO through formation of peroxynitrite are inhibited. The iNOS inhibitor can reduce the levels of NO, but ROS such as superoxide remain elevated. These ROS can react with the 'constitutively' produced NO, leading to the observed unchanged 3nitrotyrosine (3-NT) levels in patients with asthma [30]. Indeed, an in vitro study using human alveolar epithelial cells of patients with severe asthma, has shown that not only nitrite, produced by iNOS, but also $\mathrm{H}_{2} \mathrm{O}_{2}$, produced by dual oxidases, are important in the formation of 3-NT [51].

Activation of the sGC/cGMP pathway on the one hand, and/or inhibition of the NO-induced formation of pro-inflammatory molecules on the other hand could be more beneficial.

\subsection{Soluble guanylyl cyclase activators and stimulators}

In several pathologies, including asthma and COPD, the $\mathrm{NO} / \mathrm{sGC}$ cGMP pathway can be compromised by the oxidized state of sGC, making it unresponsive to both endogenous and exogenous NO. Therefore, an NO-independent treatment could be recommended in these diseases [40]. Both sGC stimulators and sGC activators are potential therapies. sGC stimulators stimulate sGC directly and enhance the sensitivity of the reduced enzyme to low levels of bioavailable NO (Fig. 2). While sGC stimulators are heme-dependent, sGC activators activate the NO-unresponsive, heme-oxidized or heme-free enzyme (Fig. 2). The efficacy of the sGC stimulator riociguat has already been shown in patients with pulmonary arterial hypertension [52]. In the same line, a recent study demonstrated that treatment of two different CS-exposed animal models with sGC stimulators riociguat (BAY 63-2521) or BAY 412272 prevent CS-induced pulmonary hypertension and emphysema [53].

BAY58-2667 (or cinaciguat) is a potent NO-independent sGC activator, replacing the weakly bound oxidized heme of $\mathrm{SGC}$, leading to activation of the enzyme; while reduced hemeis unresponsive to BAY58-2667 [40]. Treating CS-exposed mice with BAY58-2667 restored the sGC/cGMP pathway and significantly attenuated the CS-induced AHR compared with sham-treated mice [45], denoting sGC as a promising pharmaceutical target of obstructive airway diseases (Fig. 2).

\section{Concluding remarks}

The use of NO-donors and iNOS inhibitors as a treatment in obstructive airway diseases has not been successful. The specific activation of the sGC/cGMP pathway by treating patients with an sGC activator or stimulator may be a new therapeutic approach in obstructive lung diseases. The results of using SGC activators and sGC stimulators in animal models of asthma and COPD are promising, however further research is needed. Treatment by the inhaled route should be investigated to limit potential side-effects of systemic drug administration.

\section{Acknowledgments}

This work was supported by the Concerted Research Action of the University of Ghent (BOF 14-GOA-027; Ghent, Belgium), by the Fund for Scientific Research Flanders (Project G.0195.09 and G.0194.10; Brussels, Belgium) and by the Interuniversity Attraction Poles Program/Belgian State/Belgian Science Policy (P7/30; Brussels, Belgium). L.L. Dupont is a beneficiary from a Bijzonder Onderzoeksfonds Research grant from Ghent University. K.R. Bracke is a Postdoctoral Fellow of the Fund for Scientific Research Flanders. C. Glynos was supported by EU grant (Call: FP7REGPOT2011-1): "establishment of a centre of excellence for structured-based drug target characterization: strengthening the research capacity of South-Eastern Europe" (SEE-DRUG, www. seedrug.upatras.gr). P. Brouckaert is supported by the COST Action BM1005 (European Network on Gasotransmitters).

\section{References}

[1] Szabo C. Gaseotransmitters: new frontiers for translational science. Sci Transl Med 2010;2(59):ps4.

[2] Mustafa AK, Gadalla MM, Snyder SH. Signaling by gasotransmitters. Sci Signal 2009;2:re2.

[3] van der Vliet A, Eiserich JP, Cross CE. Nitric oxide: a pro-inflammatory mediator in lung disease? Respir Res 2000;1:67-72.

[4] Redington AE. Modulation of nitric oxide pathways: therapeutic potential in asthma and chronic obstructive pulmonary disease. Eur J Pharmacol 2006;533:263-76.

[5] Gustafsson LE, Leone AM, Persson MG, Wiklund NP, Moncada S. Endogenous nitric-oxide is present in the exhaled air of rabbits, guinea-pigs and humans. Biochem Biophys Res Commun 1991;181:852-7.

[6] Lucas KA, Pitari GM, Kazerounian S, Ruiz-Stewart I, Park J, Schulz S, et al. Guanylyl cyclases and signaling by cyclic GMP. Pharmacol Rev 2000;52: 375-414.

[7] Bredt DS. Nitric oxide signaling specificity - the heart of the problem. J Cell Sci 2003:116:9-15.

[8] Fleming I. Molecular mechanisms underlying the activation of eNOS. Pflugers Arch Eur J Physiol 2010;459:793-806.

[9] Asano K, Chee CB, Gaston B, Lilly CM, Gerard C, Drazen JM, et al. Constitutive and inducible nitric oxide synthase gene expression, regulation, and activity in human lung epithelial cells. Proc Natl Acad Sci U S A 1994;91:10089-93.

[10] Brindicci C, Kharitonov SA, Ito M, Elliott MW, Hogg JC, Barnes PJ, et al. Nitric oxide synthase isoenzyme expression and activity in peripheral lung tissue of patients with chronic obstructive pulmonary disease. Am J Respir Crit Care Med 2010;181:21-30.

[11] Förstermann U, Boissel J-p, Kleinert H. Expressional control of the 'constitutive' isoforms of nitric oxide synthase (NOS I and NOS III). FASEB J 1998;12: 773-90.

[12] Guo FH, Deraeve HR, Rice TW, Stuehr DJ, Thunnissen FBJM, Erzurum SC. Continuous nitric-oxide synthesis by inducible nitric-oxide synthase in normal human airway epithelium in-vivo. Proc Natl Acad Sci U S A 1995;92: 7809-13.

[13] Lundberg JO, Weitzberg E. NO generation from nitrite and its role in vascular control. Arterioscler Thromb Vasc biol 2005;25:915-22.

[14] Ansarin K, Chatkin JM, Ferreira IM, Gutierrez CA, Zamel N, Chapman KR. Exhaled nitric oxide in chronic obstructive pulmonary disease: relationship to pulmonary function. Eur Respir J 2001:17:934-8.

[15] Brindicci C, Ito K, Resta O, Pride NB, Barnes PJ, Kharitonov SA. Exhaled nitric oxide from lung periphery is increased in COPD. Eur Respir J 2005;26:52-9.

[16] Ricciardolo FL, Caramori G, Ito K, Capelli A, Brun P, Abatangelo G, et al. Nitrosative stress in the bronchial mucosa of severe chronic obstructive pulmonary disease. J Allergy Clin Immunol 2005;116:1028-35.

[17] Maestrelli P, Páska C, Saetta M, Turato G, Nowicki Y, Monti S, et al. Decreased haem oxygenase- 1 and increased inducible nitric oxide synthase in the lung of severe COPD patients. Eur Respir J 2003;21:971-6.

[18] Tadié J-M, Henno P, Leroy I, Danel C, Naline E, Faisy C, et al. Role of nitric oxide synthase/arginase balance in bronchial reactivity in patients with chronic obstructive pulmonary disease. Am J Phys 2008;294. L489-L97.

[19] Seimetz M, Parajuli N, Pichl A, Veit F, Kwapiszewska G, Weisel Friederike C, et al. Inducible NOS inhibition reverses tobacco-smoke-induced emphysema and pulmonary hypertension in mice. Cell 2011;147:293-305.

[20] Knudsen L, Atochina-Vasserman EN, Guo CJ, Scott PA, Haenni B, Beers MF, et al. NOS2 is critical to the development of emphysema in Sftpd deficient mice but does not affect surfactant homeostasis. PLoS One 2014;9:e85722. 
[21] Boyer L, Plantier L, Dagouassat M, Lanone S, Goven D, Caramelle P, et al. Role of nitric oxide synthases in elastase-induced emphysema. Lab Invest 2011;91: $353-62$.

[22] Alving K, Weitzberg E, Lundberg JM. Increased amount of nitric oxide in exhaled air of asthmatics. Eur Respir J 1993;6:1368-70.

[23] Persson MG, Zetterstrom O, Agrenius V, Ihre E, Gustafsson LE. Single-breath nitric oxide measurements in asthmatic patients and smokers. Lancet 1994;343:146-7.

[24] Kharitonov SA, Yates D, Robbins RA, Logan-Sinclair R, Shinebourne EA, Barnes PJ. Increased nitric oxide in exhaled air of asthmatic patients. Lancet 1994;343:133-5.

[25] Brindicci C, Ito K, Barnes PJ, Kharitonov SA. Effect of an inducible nitric oxide synthase inhibitor on differential flow-exhaled nitric oxide in asthmatic patients and healthy volunteers. Chest 2007;132:581-8.

[26] Saleh D, Ernst P, Lim S, Barnes PJ, Giaid A. Increased formation of the potent oxidant peroxynitrite in the airways of asthmatic patients is associated with induction of nitric oxide synthase: effect of inhaled glucocorticoid. FASEB ] 1998; 12:929-37.

[27] Hamid Q, Springall DR, Riveros-Moreno V, Chanez P, Howarth P, Redington A, et al. Induction of nitric oxide synthase in asthma. Lancet 1993:342:1510-3.

[28] Smith AD, Cowan JO, Brassett KP, Filsell S, McLachlan C, Monti-Sheehan G, et al. Exhaled nitric oxide: a predictor of steroid response. Am J Respir Crit Care Med 2005;172:453-9.

[29] Redington AE, Meng Q-H, Springall DR, Evans TJ, Créminon C, Maclouf J, et al. Increased expression of inducible nitric oxide synthase and cyclo-oxygenase2 in the airway epithelium of asthmatic subjects and regulation by corticosteroid treatment. Thorax 2001;56:351-7.

[30] Singh D, Richards D, Knowles RG, Schwartz S, Woodcock A, Langley S, et al. Selective inducible nitric oxide synthase inhibition has no effect on allergen challenge in asthma. Am J Respir Crit Care Med 2007:176:988-93.

[31] Landgraf RG, Russo M, Jancar S. Acute inhibition of inducible nitric oxide synthase but not its absence suppresses asthma-like responses. Eur J Pharmacol 2005;518:212-20.

[32] Xiong Y, Karupiah G, Hogan SP, Foster PS, Ramsay AJ. Inhibition of allergic airway inflammation in mice lacking nitric oxide synthase 2. J Immunol 1999; 162:445-52.

[33] Bargagli E, Olivieri C, Bennett D, Prasse A, Muller-Quernheim J, Rottoli P. Oxidative stress in the pathogenesis of diffuse lung diseases: a review. Respir Med 2009;103:1245-56.

[34] Nathan C, Cunningham-Bussel A. Beyond oxidative stress: an immunologist's guide to reactive oxygen species. Nat Rev Immunol 2013:13:349-61.

[35] Kirkham PA, Barnes PJ. Oxidative stress in COPD. Chest 2013;144:266-73.

[36] Holguin F. Oxidative stress in airway diseases. Ann Am Thorac Soc 2013;10. S150-S7.

[37] Kharitonov SA, Barnes PJ. Exhaled markers of pulmonary disease. Am J Respir Crit Care Med 2001;163:1693-722.

[38] Osoata GO, Hanazawa T, Brindicci C, Ito M, Barnes PJ, Kharitonov S, et al Peroxynitrite elevation in exhaled breath condensate of copd and its inhibition by fudosteine. Chest 2009;135:1513-20.
[39] Hamad AM, Clayton A, Islam B, Knox AJ. Guanylyl cyclases, nitric oxide, natriuretic peptides, and airway smooth muscle function. Am J Physiol Lung Cell Mol Physiol 2003;285:L973-83.

[40] Evgenov OV, Pacher P, Schmidt PM, Hasko G, Schmidt HH, Stasch JP. NO-independent stimulators and activators of soluble guanylate cyclase: discovery and therapeutic potential. Nat Rev Drug Discov 2006:5:755-68.

[41] Mergia E, Russwurm M, Zoidl G, Koesling D. Major occurrence of the new alpha2beta1 isoform of NO-sensitive guanylyl cyclase in brain. Cell Signal 2003:15:189-95.

[42] Friebe A, Koesling D. Regulation of nitric oxide-sensitive guanylyl cyclase. Circ Res 2003;93:96-105.

[43] Francis SH, Busch JL, Corbin JD, Sibley D. cGMP-dependent protein kinases and cGMP phosphodiesterases in nitric oxide and cGMP action. Pharmacol Rev 2010;62:525-63.

[44] Papapetropoulos A, Simoes DC, Xanthou G, Roussos C, Gratziou C. Soluble guanylyl cyclase expression is reduced in allergic asthma. Am J Physiol Lung Cell Mol Physiol 2006;290:L179-84.

[45] Glynos C, Dupont LL, Vassilakopoulos T, Papapetropoulos A, Brouckaert P Giannis A, et al. The role of soluble guanylyl cyclase in chronic obstructive pulmonary disease. Am J Respir Crit Care Med 2013;188:789-99.

[46] Toward TJ, Smith N, Broadley KJ. Effect of phosphodiesterase-5 inhibitor, sildenafil (viagra), in animal models of airways disease. Am J Respir Crit Care Med 2004;169:227-34.

[47] Wang T, Liu Y, Chen L, Wang X, Hu XR, Feng YL, et al. Effect of sildenafil on acrolein-induced airway inflammation and mucus production in rats. Eur Respir J 2009;33:1122-32.

[48] Clayton R, Dick C, Mackenzie A, Nagasawa M, Galbraith D, Hastings S, et al. The effect of selective phosphodiesterase inhibitors, alone and in combination, on a murine model of allergic asthma. Respir Res 2004;5:4.

[49] Goudie AR, Lipworth BJ, Hopkinson PJ, Wei L, Struthers AD. Tadalafil in patients with chronic obstructive pulmonary disease: a randomised, doubleblind, parallel-group, placebo-controlled trial. Lancet Respir Med 2014;2: 293-300.

[50] Blanco I, Gimeno E, Munoz PA, Pizarro S, Gistau C, Rodriguez-Roisin R, et al. Hemodynamic and gas exchange effects of sildenafil in patients with chronic obstructive pulmonary disease and pulmonary hypertension. Am J Respir Crit Care Med 2010;181:270-8.

[51] Voraphani N, Gladwin MT, Contreras AU, Kaminski N, Tedrow JR, Milosevic J et al. An airway epithelial iNOS-DUOX2-thyroid peroxidase metabolome drives Th1/Th2 nitrative stress in human severe asthma. Mucosal Immunol 2014. http://dx.doi.org/10.1038/mi.2014.6 [Epub ahead of print].

[52] Ghofrani HA, Galie N, Grimminger F, Grunig E, Humbert M, Jing ZC, et al Riociguat for the treatment of pulmonary arterial hypertension. N Engl J Med 2013;369:330-40.

[53] Weissmann N, Lobo B, Pichl A, Parajuli N, Seimetz M, Puig-Pey R, et al. Stimulation of soluble guanylate cyclase prevents cigarette smoke-induced pulmonary hypertension and emphysema. Am J Respir Crit Care Med 2014;189:1359-73. 